\title{
Metal Plasticity and Fatigue at High Temperature
}

\author{
Denis Benasciutti ${ }^{1, *(\mathbb{D}}$, Luciano Moro ${ }^{2}$ and Jelena Srnec Novak ${ }^{2, *(\mathbb{D}}$ \\ 1 Department of Engineering, University of Ferrara, via Saragat 1, 44122 Ferrara, Italy \\ 2 Politechnic Department of Engineering and Architecture (DPIA), University of Udine, via delle Scienze 208, \\ 33100 Udine, Italy; luciano.moro@uniud.it \\ * Correspondence: denis.benasciutti@unife.it (D.B.); jelena.srnec@uniud.it (J.S.N.); \\ Tel.: +39-(0)532-974-976 (D.B.); +39-0432-558-297 (J.S.N.)
}

Received: 10 February 2020; Accepted: 26 February 2020; Published: 1 March 2020

\section{Introduction and Scope}

The situation in which a component or structure is maintained at high temperature under the action of cyclic thermal and/or mechanical loadings represents, perhaps, one of the most demanding engineering applications - if not, in fact, the most demanding one. Examples can be found in many industrial fields, such as automotive (cylinder head, engine, disk brakes), steel-making (hot rolling), machining (milling, turning), aerospace (turbine blades), and fire protection systems (fire doors).

The presence of high temperatures usually induces some amount of material plasticity or creep deformation in the most stressed regions of the structure. Plasticity, if combined with the action of cyclic loading variation, may lead to low-cycle fatigue (LCF) failure.

In order to estimate the component fatigue life in such demanding operative condition, it is often necessary to characterize the high-temperature material behavior under cyclic loading, in terms, for example, of cyclic stress-strain response, strain hardening or softening, creep behavior, experimental fatigue strength under isothermal and/or non-isothermal conditions. Moreover, it is also necessary to develop a reliable structural durability approach that is able to include experimental results in numerical and/or predictive models (e.g., plasticity models, fatigue strength curves).

The choice of the most appropriate material model to be used in simulations, or even calibrating the model to experimental data, often represents the most critical step in the whole design approach. Experimental techniques and modeling have to be properly managed to guarantee the reliability of the estimated fatigue life.

\section{Contributions}

As a part of this Special Issue, researchers were invited to submit their innovative research papers aimed at providing a state-of-the-art knowledge on the topic of metal plasticity, creep deformation and fatigue strength of metals operating at high temperatures, with emphasis on both experimental characterization and numerical modeling of material behavior. A total of eleven research papers were published [1-11].

Problems correlated with the creep phenomenon have been investigated in $[1,2]$. The paper by Liu et al. [1] presents an explicit fatigue-creep model which develops one formulation that covers the full range of conditions: from pure fatigue, to creep-fatigue up to pure creep. Kloc et al. [2] study a complex phenomenological creep model with particular attention focused on transient effects in the creep behavior of the Sanicro 25 steel.

In the paper by Aigner et al. [3] a model based on the $\sqrt{\text { area }}$ concept proposed by Murakami is extended to elevated temperature by introducing an additional exponent.

Poulain et al. [4] examine the dependence and interaction between the effect of pressurized water reactors environment, strain rate and shape of loading waveform on the LCF resistance of a 304L steel in terms of stress-strain response, crack growth, fatigue life and fracture surfaces morphology. 
Thermo-mechanical fatigue (TMF) is studied in [5-7]. The paper written by Szmytka et al. [5] provides an overview of a TMF design protocol through the analysis of the specific case of a cylinder head, which summarizes the studies led by the authors over the last five years. Four typical issues in high-temperature design—loading identification, aging and constitutive models, TMF criteria, and validation tests-are addressed and critically analyzed, while some improvements are proposed. In [6], Wagner et al. work on the identification of a criterion for crack initiation to provide the basis for a nondestructive quality control of TMF-loaded porous components with improved statistical safety. The paper by Ghodrat et al. [7] presents an adapted version of Paris' fatigue crack-growth law where cyclic plastic strains at the crack tip are considered as the parameter that controls crack growth. Finally, it is found that the modified Paris' law is able to assess TMF lifetimes of spheroidal graphite iron (SGI) very well for all constraint levels with a single set of parameters. Crack initiation life models are studied in [8], where three approaches (one based on Weibull distributed crack initiation life, the other two based on probabilistic Schmid factor) are presented.

The effect of ageing temperature, initial stress levels and pre-strains on the stress-relaxation ageing behavior of aluminium alloy AA7150-T7751 are investigated through a series of experiments and presented in the work of Cai et al. [9]. The authors discuss a stress relaxation constitutive model with the ability to reproduce stress relaxation curves under different process conditions. The paper by Testa et al. [10] describes a model to estimate the yield stress at different strain rates and temperatures for metals with body-centered-cubic (bcc) structure. Srnec Novak et al. [11] develop a new isotropic model to describe the cyclic hardening/softening plasticity behavior of metals. The proposed model is described with three parameters which were calibrated based on LCF experimental data of $\mathrm{CuAg}$ alloy. An improvement is observed with respect to another nonlinear isotropic model generally used in the literature.

Papers in this Special Issue addressed different types of material, from stainless steel studied by $[1,2,4,10]$, to aluminum alloys investigated by $[3,6,9]$, Ni-based supper alloy in [8], spheroidal graphite iron by [7], and copper alloy discussed in [11].

The developed constitutive methods have, in most cases, been compared to experimental data obtained with tensile tests [3], fatigue tests [3,4,8], TMF tests [6,7], creep tests [2], and stress relaxation, aging tests presented in [9].

\section{Conclusions}

This Special Issue presents a collection of research articles covering the relevant topics in the field of metals plasticity, creep and fatigue at high temperature. As Guest Editors, we hope that these articles may be useful to scientists working in this field to deepen or widen their research.

Acknowledgments: As Guest Editors, we thank all authors who contributed to this Special Issue with high-quality manuscripts that shared results of their research activities. Thanks to Assistant Editor Kinsee Guo for his valuable and inexhaustible support during the preparation of this issue, and thanks also to all staff members of Metals Editorial Office for their management and practical support in the publication process of this issue.

Conflicts of Interest: The authors declare no conflict of interest.

Dedication: This Special Issue is dedicated to the memory of Luciano Moro. He was a promising researcher, a colleague, a friend.

\section{References}

1. Liu, D.; Pons, D.J. An explicit creep-fatigue model for engineering design purposes. Metals 2018, 8, 853. [CrossRef]

2. Kloc, L.; Sklenicka, V.; Dymacek, P. Transient effect in creep of Sanicro 25 austenitic steel and their modelling. Metals 2019, 9, 245. [CrossRef]

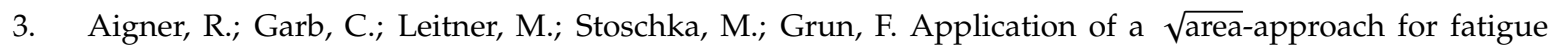
assessment of cast aluminum alloys at elevated temperature. Metals 2018, 8, 1033. [CrossRef] 
4. Poulain, T.; de Baglion, L.; Mendez, J.; Henaff, G. Influence of strain rate and waveshape on environmentally-assisted cracking during low-cycle fatigue of a 304L austenitic stainless steel in a PWR water environment. Metals 2019, 9, 197. [CrossRef]

5. Szmytka, F.; Osmond, P.; Remy, L.; Masson, P.D.; Forre, A.; Hocke, F.X. Some recent advances on thermal-mechanical fatigue design and upcoming challenges for the automotive industry. Metals 2019, 9, 794. [CrossRef]

6. Wagner, M.; Mosenbacher, A.; Eiber, M.; Hoyer, M.; Riva, M.; Christ, H.J. Thermomechanical fatigue of lost foam cast Al-Si cylinder heads-assessment of crack origin based on the evaluation of pore distribution. Metals 2019, 9, 821. [CrossRef]

7. Ghodrat, S.; Kalra, A.; Kestens, L.A.I.; Riemslag, T.A.C. Thermo-mechanical fatigue lifetime assessment of spheroidal cast iron at different thermal constraint levels. Metals 2019, 9, 1068. [CrossRef]

8. Engel, B.; Made, L.; Lion, P.; Moch, N.; Gottschalk, H.; Beck, T. Probabilistic modeling of slip system-based shear stresses and fatigue behavior of coarse-grained Ni-based superalloy considering local grain anisotropy and grain orientation. Metals 2019, 9, 813. [CrossRef]

9. Cai, Y.; Zhan, L.; Xu, Y.; Liu, C.; Wang, J.; Zhao, X.; Xu, L.; Tong, C.; Jin, G.; Wang, Q.; et al. Stress relaxation aging behavior and constitutive modelling of AA7150-T7751 under different temperatures, initial stress levels and pre-strains. Metals 2019, 9, 1215. [CrossRef]

10. Testa, G.; Bonora, N.; Ruggiero, A.; Iannitti, G. Flow stress of bcc metals over a wide range of temperature and strain rates. Metals 2020, 10, 120. [CrossRef]

11. Srnec Novak, J.; De Bona, F.; Benasciutti, D. An isotropic model for cyclic plasticity calibration on the whole shape of hardening/softening evolution curve. Metals 2019, 9, 950. [CrossRef]

(C) 2020 by the authors. Licensee MDPI, Basel, Switzerland. This article is an open access article distributed under the terms and conditions of the Creative Commons Attribution (CC BY) license (http://creativecommons.org/licenses/by/4.0/). 